\title{
FORECASTING MODEL OF GHG EMISSION IN MANUFACTURING SECTORS OF THAILAND
}

\author{
Pruethsan Sutthichaimethee ${ }^{1}$, Danupon Ariyasajjakorn ${ }^{1}$ \\ 1 Faculty of Economics, Chulalongkorn University, Thailand, e-mail: pruethsan@gmail.com, Danupon.A@ \\ Chula.ac.th
}

Received: 2016.11.03

Accepted: 2016.12.08

Published: 2017.01.01

\begin{abstract}
The aim of this study is to analyze the modeling and forecasting the GHG emission of energy consumption in manufacturing sectors. The scope of the study is to analyse energy consumption and forecasting GHG emission of energy consumption for the next 10 years (2016-2025) and 25 years (2016-2040) by using ARIMAX model from the Input-output table of Thailand. The result shows that iron and steel has the highest value of energy consumption and followed by cement, fluorite, air transport, road freight transport, hotels and places of loading, coal and lignite, petrochemical products, other manufacturing, road passenger transport, respectively. The prediction results show that these models are effective in forecasting by measured by using RMSE, MAE, and MAPE. The results forecast of each model is as follows: 1$)$ Model $1(2,1,1)$ shows that GHG emission will be increasing steadily and increasing at $25.17 \%$ by the year 2025 in comparison to 2016. 2) Model $2(2,1,2)$ shows that GHG emission will be rising steadily and increasing at $41.51 \%$ by the year 2040 in comparison to 2016 .
\end{abstract}

Keywords: manufacturing sectors; environment cost; energy consumption; GHG emission; multiplier

\section{INTRODUCTION}

Economic continued growing to be a very high GDP per capita is an important goal of the all countries [Asian Development Bank (ADB) 2014] those aims so as their own country is a country in the Annex 1 group and at the same issue of environment, it is a problem that the whole world is experiencing continuous, say that: economic, social are growth but environmental decline [ADB 2014, Thailand Development Research Institute (TDRI) 2007, Office of the National Economic and Social Development Board (NESDB) 2015] it was mainly coming from energy consumption and resulting greenhouse gas increase more, then the catalyst for climate change itself.

Climate change is happening and the impact on all countries [TDRI 2007]. Greenhouse gas was mainly caused by negative phenomena that affect to the world in all aspects of economic, social and environmental likely raising steadily
[Azadeh et al. 2011, Pappas et al. 2008], especially in developing countries. Although various organizations attempt to find a solution to the problem [Zhao and Magoulès 2012]. This can be observed from the global temperature rise from 1.1 to 6.0 degree Celsius [ADB 2014].

Thailand, as one of the rapidly developing nations, has steadily increased its GDP from 2000 until 2015 [ADB 2014]. The sector that generates the highest revenue for the country is manufacturing sector [TDRI 2007, NESDB 2015]. It was found that the sector had an increase in growth rate [Lee and Tong 2011] from 3.79\% in (2000) to $46.71 \%$ in (2015) [NESDB 2015]. Over 90 percent of the production is for export and 10 percent of the production is for domestic consumption [ADB 2014, NESDB 2015]. Therefore, it causes huge revenues and cash inflows to the country from this sector [ADB 2014, Barak et al. 2015, Suganthi and Samuel 2012]. However, manufacturing sectors also has a high environmental cost 
as well (66\%), especially energy cost as shown in Figure 1 [Hao et al. 2012, Alizadeh et al. 2012, Lee and Tong 2012]. It similarly effects negatively the environment as well [Lee and Tong 2011]. For the above reason, it is an indicator for the government to plan for the nation effectively and sustainably [Ekonomou, 2010].

This study has foreseen the problems that arise from energy consumption in manufacturing sectors. The study of forecasting of energy consumption is made in order to help decision making on the further operation plans [Mamlook et al. 2009, Azadeh et al. 2010, Suganthi et al. 2015]. In addition, the study of related research or review literature did not find any study that had been analyzed in any such a way. Thus, it is an important reason that the study results can be carried out in the national administration both in Thailand and applied in other countries worldwide.

Emission in 2015 by energy sector (\%)

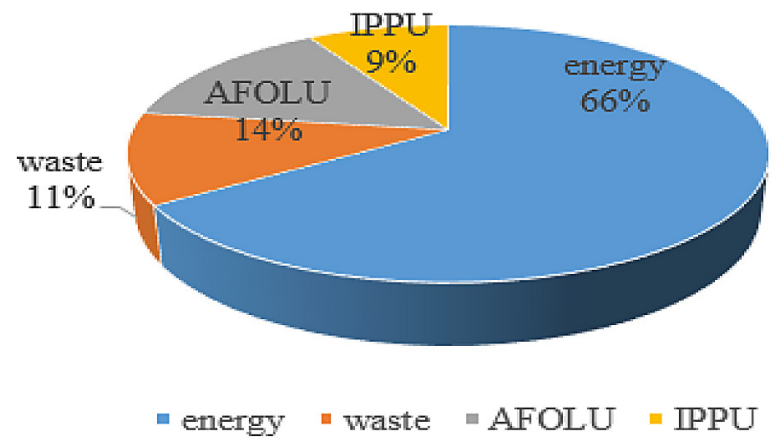

Figure 1. The proportion of GHG emissions by sector

\section{MODEL AND METHODOLOGY}

\section{Input-output model}

The model in this study is related to the InputOutput Table, in which the relationship of the data are categorized by rows and columns as follows in Table 1 [Leontief 1986].
Rows present output distribution of product sector $\mathrm{i}$ for $\mathrm{n}$ product sectors and the Gross product of product sector i can be defined, for $1 \leq i \leq n$, by

$$
X_{i}=\sum_{j=1}^{n} X_{i j}+F_{i}
$$

where: $X_{i}$ - refers to Gross product of product sector $i$,

$X_{i j}$ - refers to product distribution of product sector i of goods and services production for product sector $j$,

$F_{i}-$ refers to the final demand of product sector i.

Columns show the structure of expense or cost of goods production for product sector $\mathrm{j}$ (Xi) that can be defined, for $1 \leq j \leq n$ by

$$
X_{i}=\sum_{j=1}^{n} X_{i j}+V_{j}
$$

where: $V_{j}$ - refers to value added of product sector $j$, only if input value is directly proportional to output value.

Then $X_{i j}$ can be defined by the relationship of output $(X)$, input coefficient $(A)$ and final demand $(F)$ of production structure for an economic system that can be defined by

$$
\begin{gathered}
X=A X+F \\
X=[I-A]^{-1} F
\end{gathered}
$$

Where $[I-A]^{-1}$ is the Leontief Inverse Matrix (or inverse matrix), which is important for economic system analysis when using the InputOutput Table. The inverse matrix acts as a direct and indirect input coefficient of a production supply chain that can be used for supply chain length and intensity calculation. Environmental Cost of the production of each good or service

\begin{tabular}{|c|c|c|c|c|c|c|c|c|}
\hline \multirow{2}{*}{\multicolumn{2}{|c|}{ Producing sector }} & \multicolumn{2}{|c|}{ Processing sectors } & \multirow{2}{*}{\multicolumn{4}{|c|}{ Final demand }} & \multirow{3}{*}{\begin{tabular}{|c|}
$\begin{array}{c}\text { Total outputs } \\
(\mathrm{X})\end{array}$ \\
$X_{1}$ \\
\end{tabular}} \\
\hline & & \multirow{2}{*}{$\frac{1}{X_{11}}$} & \multirow{2}{*}{2} & & & & & \\
\hline \multirow{2}{*}{$\begin{array}{l}\text { Processing } \\
\text { sectors }\end{array}$} & 1 & & & $C_{1}$ & $i_{1}$ & $g_{1}$ & $e_{1}$ & \\
\hline & 2 & $X_{21}$ & $X_{22}$ & $C_{2}$ & $i_{2}$ & $g_{2}$ & $e_{2}$ & $X_{2}$ \\
\hline \multirow{3}{*}{$\begin{array}{c}\text { Payments } \\
\text { sectors }\end{array}$} & Value added & $l_{1}$ & $l_{2}$ & $l_{\mathrm{c}}$ & $l_{1}$ & $l_{\mathrm{g}}$ & $l_{\mathrm{e}}$ & $L$ \\
\hline & & $n_{1}$ & $n_{2}$ & $n_{\mathrm{c}}$ & $n_{1}$ & $n_{\mathrm{g}}$ & $n_{\mathrm{e}}$ & $N$ \\
\hline & Imports & $m_{1}$ & $m_{2}$ & $m_{\mathrm{c}}$ & $m_{1}$ & $m_{\mathrm{g}}$ & $m_{\mathrm{e}}$ & $M$ \\
\hline \multicolumn{2}{|c|}{ Total outlays (X') } & $X_{1}$ & $X_{2}$ & $\mathrm{C}$ & $I$ & $G$ & $E$ & $X$ \\
\hline
\end{tabular}
can be calculated using the multiplication of the Environmental Cost coefficient and the inverse

Table 1. Matrix used to create the Input-Output table of production sectors 
matrix. Finally, the result represents the total effect of a supply chain by giving the accumulated Environmental Cost of each good produced. The result also shows the intensity of backward environmental effects of direct and indirect inputs and outputs. Furthermore, the result presents names, sectors and intensities of Environmental Costs that are useful to formulate an efficient policy and in environmental problem solving.

Relationships in the Input-Output Table affects the output of each product sector $(\Delta \mathrm{F})$, which is called the Multiplier for Final goods and services. Equation (5) presents the calculation of the Multiplier.

$$
\Delta X=[I-A]^{-1} \Delta F
$$

If final demand $(\Delta \mathrm{F})$ increases, Environmental Cost will increase $(\Delta \mathrm{E})$. Equation (6) calculates the increase of Environmental Cost.

$$
\Delta E=R[I-A]^{-1} \Delta F
$$

\section{ARIMA Model}

ARIMA models obtained from a combination of autoregressive and moving average models. For modelling seasonal time series beside nonseasonal series, $\operatorname{ARIMA}(p, d, q)(P, D, Q) \bullet$ is known as multiplicative ARIMA model is defined as follows:

$$
\begin{aligned}
\left(1-\Phi_{1} B^{\varphi}-\Phi_{2} B^{2 \varphi}-\ldots-\Phi_{p} B^{p \varphi}\right)\left(1-\varphi_{1} B-\varphi_{2} B^{2}\right. & \\
& \left.-\varphi_{p} B^{p}\right)\left(1-B^{\varphi}\right)^{D}(1-B)^{d} Z_{t} \\
= & \left(1-\Theta_{1} B^{\varphi}-\Theta_{2} B^{2 \varphi}-\ldots-\Theta_{Q} B^{Q \varphi}\right) \\
& \left(1-\theta_{1} B-\theta_{2} B^{2}-\ldots \theta_{q} B^{q}\right) \varepsilon_{t}
\end{aligned}
$$

where: $\varepsilon_{t}-$ the random variable,

$\mathscr{Q}$ - the periodic term,

$B$ - the difference operator as $B(Z)=Z_{t-1}$, $\left(1-B^{\varpi}\right)^{D}$ - the $D^{\text {th }}$ seasonal difference measure $Q$,

$d=(1-B)^{d}-$ the $d^{\text {th }}$ non-seasonal difference,

$p$ - the order of non-seasonal autoregressive model,

$q$ - the order of non-seasonal moving average model,

$P$ - the order of seasonal autoregressive model,

$Q$ - the order of seasonal moving average model,

$\phi$ - the parameter of non-seasonal autoregressive model, $\theta$ - is the parameter of non-seasonal moving average model,

$\Phi-$ is the parameter of seasonal autoregressive model,

$\Theta$ - is the seasonal moving average mod-

el [Pappas et al. 2010].

It should be noted that, in Equation 7 when $d$ $=\mathrm{D}=0$, ARIMA model becomes ARMA model. The next stage is determining the number of ARMA and ARIMA models parameters that perform by Partial Auto Correlation Function (PACF) and Auto Correlation function (ACF) curves [Assaad et al. 2008]. Other parameters that should be determined are $d$ and $D$, which de- fined for ARIMA models. These parameters were considered in practice maximum one or two [Mamlook et al. 2009]. Due to the number of possible scenarios for the parameters, $p=P=q=Q=\{0,1,2,3,4\}$.

\section{RESULTS AND DISCUSSION}

The results of the energy consumption are classified by each category of the production. Table 2 lists top ten manufacturing sectors in terms of energy consumption. The result shows that iron and steel has the highest value of energy consumption and followed by cement, fluorite, air transport, road freight transport, hotels and places of loading, coal and lignite, petrochemical products, other manufacturing, road passenger transport, respectively. The average carrying capacity value for environmental cost in terms of energy consumption, 0.079 . If energy consumption for a particular sector is lower than the average carrying capacity value, there is further capacity for production. Energy consumption values that are

Table 2. The priority arising from energy consumption in manufacturing sectors

\begin{tabular}{|c|l|}
\hline \multicolumn{2}{|c|}{ Energy consumption } \\
\hline Multiplier value & \multicolumn{1}{|c|}{ Sectors } \\
\hline 0.492 & Iron and steel \\
\hline 0.489 & Cement \\
\hline 0.464 & Fluorite \\
\hline 0.416 & Air transport \\
\hline 0.356 & Road freight transport \\
\hline 0.326 & Hotels and places of loading \\
\hline 0.318 & Coal and lignite \\
\hline 0.312 & Petrochemical products \\
\hline 0.301 & Other manufacturing \\
\hline 0.301 & Road passenger transport \\
\hline
\end{tabular}


higher than the average carrying capacity value signify that there is no further capacity for production. The sectors with the highest energy consumption were all sectors. Energy consumption indicator was above the average carrying capacity value, signifying that this sector does not have capacity for further production.

The results of the forecasting model the GHG emission is classified by each category of the production. This research can be summarized as following:

1) Unit Root Test: with the Augmented DickeyFuller test is shown in Table 3.

The ADF Test Statistic at level of all variables has a variable unit root component or Non Stationary i.e. the value calculated from the ADF, all lower than the critical value. From the table at the significance level of $1 \%, 5 \%$ and $10 \%$, so that it must be to qualify as Stationary by the difference moment. This research found that all variables Stationary at the first differencing included greenhouse gas(GHG), population(Population), technology(Tech), carbon dioxide $\left(\mathrm{CO}_{2}\right)$, methane $\left(\mathrm{CH}_{4}\right)$, nitrous oxide $\left(\mathrm{N}_{2} \mathrm{O}\right)$ and GDP per capita (GDP). The value of the test based on the "Tau-test" is greater than the all "Tau-critical" at the first difference, results in Table 4.

2) Result of the Co-integration test

The result in Table 4 bring all variables are Stationary at the first difference to test Co-inte- gration by using the method of "Johansen Juselius" shown in Table 5.

Co-integration test showed that model is a Co-integration because of the Trace Test is 224.25 , which is higher than the critical value at significance level of $1 \%$ and $5 \%$, the Maximum Eigen value test at 146.68 which is higher than the critical value significance level of $1 \%$ and $5 \%$.

3) The results of ARIMAX Model

- ARIMAX Model $1(2,1,1)$

$\Delta \ln (G H G)_{t}=$

$=-0.021+3.98 \Delta \ln (G H G) *{ }_{t-1}+5.74 \Delta \ln (G H G) *{ }_{t-2}+$

$4.34 \Delta \ln$ Population $* *_{t-1}-7.87 \Delta \ln ($ Tech $) *{ }_{t-1}+$ $5.23 \Delta \ln \left(\mathrm{CO}_{2}\right) *{ }_{t-1}+3.79 \Delta \ln \left(\mathrm{CH}_{4}\right) *{ }_{t-1}+$ $4.06 \Delta \ln \left(N_{2} O\right) *{ }_{t-1}+2.01 M A^{*}{ }_{1}+6.89 E C M * *$

Where: $* *$ is significance $\mathrm{a}=0.01, *$ is significance $\mathrm{a}=0.05$, R-squared is 0.95 , Adjusted $\mathrm{R}$-squared is 0.90 , Durbin-Watson stat is 2.17 , F-statistic is 207.35 (Probability is 0.00), ARCHtest is 39.66 (Probability is 0.11 ), LM - test is 1.89 (Probability is 0.12 ) and response test $\left(\chi^{2}>\right.$ critical) is significance.

- ARIMAX Model $1(2,1,2)$

$\Delta \ln (G H G)_{t}=$

$=-0.101+2.18 \Delta \ln (G H G){ }_{t-1}+3.74 \Delta \ln (G H G) *{ }_{t-2}+$

$3.98 \Delta \ln$ Population $*{ }_{t-2}-3.69 \Delta \ln ($ Tech $) *{ }_{t-1}+$

$4.98 \Delta \ln \left(\mathrm{CO}_{2}\right) *{ }_{t-1}+3.78 \Delta \ln \left(\mathrm{CH}_{4}\right) *{ }_{t-1}+$

$2.95 \Delta \ln \left(N_{2} O\right){ }_{t-1}+3.89 M A * *{ }_{1}+5.12 M A^{* *}{ }_{2}+5.53 E C M * *$

Table 3. Unit Root test at level

\begin{tabular}{|c|c|c|c|c|c|c|}
\hline \multirow{2}{*}{ Variables } & \multirow{2}{*}{ Lag } & \multirow{2}{*}{ ADF Test } & \multicolumn{3}{|c|}{ MacKinnon Critical Value } & \multirow{2}{*}{ Status } \\
\cline { 4 - 7 } & & & $1 \%$ & $5 \%$ & $10 \%$ & \\
\hline $\ln (\mathrm{GHG})$ & 1 & -2.35 & -4.12 & -3.27 & -3.05 & $\mathrm{I}(0)$ \\
\hline $\ln ($ Population $)$ & 1 & -3.14 & -4.12 & -3.27 & -3.05 & $\mathrm{I}(0)$ \\
\hline $\ln (\mathrm{Tech})$ & 1 & -2.57 & -4.12 & -3.27 & -3.05 & $\mathrm{I}(0)$ \\
\hline $\ln \left(\mathrm{CO}_{2}\right)$ & 1 & -3.13 & -4.12 & -3.27 & -3.05 & $\mathrm{I}(0)$ \\
\hline $\ln \left(\mathrm{CH}_{4}\right)$ & 1 & -3.01 & -4.12 & -3.27 & -3.05 & $\mathrm{I}(0)$ \\
\hline $\ln \left(\mathrm{N}_{2} \mathrm{O}\right)$ & 1 & -2.71 & -4.12 & -3.27 & -3.05 & $\mathrm{I}(0)$ \\
\hline
\end{tabular}

Table 4. Unit Root test at the first difference

\begin{tabular}{|c|c|c|c|c|c|c|}
\hline \multirow{2}{*}{ Variables } & \multirow{2}{*}{ Lag } & \multirow{2}{*}{ ADF Test } & \multicolumn{3}{|c|}{ MacKinnon Critical Value } & \multirow{2}{*}{ Status } \\
\cline { 4 - 7 } & & & $1 \%$ & $5 \%$ & $10 \%$ & \\
\hline $\ln (\mathrm{GHG})$ & 1 & -7.65 & -4.22 & -3.36 & -3.25 & $\mathrm{I}(1)$ \\
\hline $\ln ($ Population $)$ & 1 & -5.03 & -4.22 & -3.36 & -3.25 & $\mathrm{I}(1)$ \\
\hline $\ln ($ Tech $)$ & 1 & -4.92 & -4.22 & -3.36 & -3.25 & $\mathrm{I}(1)$ \\
\hline $\ln \left(\mathrm{CO}_{2}\right)$ & 1 & -5.65 & -4.22 & -3.36 & -3.25 & $\mathrm{I}(1)$ \\
\hline $\ln \left(\mathrm{CH}_{4}\right)$ & 1 & -4.89 & -4.22 & -3.36 & -3.25 & $\mathrm{I}(1)$ \\
\hline $\ln \left(\mathrm{N}_{2} \mathrm{O}\right)$ & 1 & -6.14 & -4.22 & -3.36 & -3.25 & $\mathrm{I}(1)$ \\
\hline
\end{tabular}


Table 5. Co-integration test by Johansen Juselius

\begin{tabular}{|c|c|c|c|c|c|c|c|c|}
\hline \multirow{2}{*}{ Variables } & \multirow{2}{*}{$\begin{array}{c}\text { Hypothesized } \\
\text { No. of } \mathrm{CE}(\mathrm{S})\end{array}$} & \multirow{2}{*}{$\begin{array}{l}\text { Trace } \\
\text { Statistic } \\
\text { Test }\end{array}$} & \multicolumn{2}{|c|}{$\begin{array}{c}\text { MacKinnon Critical } \\
\text { Value }\end{array}$} & \multirow{2}{*}{$\begin{array}{l}\text { Max-Eigen } \\
\text { Statistic Test }\end{array}$} & \multicolumn{2}{|c|}{$\begin{array}{l}\text { MacKinnon } \\
\text { Critical Value }\end{array}$} & \multirow[t]{2}{*}{ Status } \\
\hline & & & $1 \%$ & $5 \%$ & & $1 \%$ & $5 \%$ & \\
\hline \multirow{2}{*}{$\begin{array}{l}\Delta \ln (\mathrm{GHG}), \Delta \ln (\text { Population }), \Delta \ln (\text { Tech }) \\
\Delta \ln \left(\mathrm{CO}_{2}\right), \Delta \ln \left(\mathrm{CH}_{4}\right), \Delta \ln \left(\mathrm{N}_{2} \mathrm{O}\right)\end{array}$} & None ${ }^{* *}$ & 224.25 & 19.75 & 15.41 & 146.68 & 15.68 & 14.07 & $\mathrm{I}(1)$ \\
\hline & At Most $1^{* *}$ & 75.77 & 5.75 & 3.16 & 79.01 & 5.75 & 3.16 & $\mathrm{I}(1)$ \\
\hline
\end{tabular}

Where: $* *$ is significance a $=0.01, *$ is significance $\mathrm{a}=0.05$, R-squared is 0.91 , Adjusted $\mathrm{R}$-squared is 0.88 , Durbin-Watson stat is 2.25, F-statistic is 169.45 (Probability is 0.00), ARCHtest is 33.71 (Probability is 0.10 ), LM - test is 1.91 (Probability is 0.10$)$ and response test $\left(\chi^{2}>\right.$ critical) is significance.

4) The results of forecasting model

When the modeling ARIMAX Model $1(2,1,1)$ and ARIMAX Model $2(2,1,2)$, which is the best model that was used to predict 2 models. The first, 10 years forecast (2016-2025), the second, 25 years forecast (2016-2040) the forecast results shown in Figures 2 and 3.

The results forecasts found that the model 1 (2016-2025) greenhouse gas volume increased steadily and average rising up to $25.17 \%$ in 2025, and the model 2 (2016-2040) greenhouse gas volume increased steadily as well and average rising to $41.51 \%$ in 2040 . However, that model 1 and model 2 were tested the effectiveness of the model compared with Actual value found that both models are highly effective with the low deviation can be used to decision making that shown in Table 6.

This study, the first of its kind in Thailand, creates the forecasting model of energy cost using ARIMAX model and from review of literature of many of sources such as Jain (2010) apply GrayMarkov model, Grey-model with rolling mechanism, and singular spectrum analysis (SSA) to forecast the consumption of conventional energy in India, Hsiai-Tien Pao et al. (2012) employ the NGBM (nonlinear grey Bernoulli model) to predict carbon emission, energy consumption and real outputs, and Weijun Xu et al. (2015) establish a new model with improved GM-ARIMA based

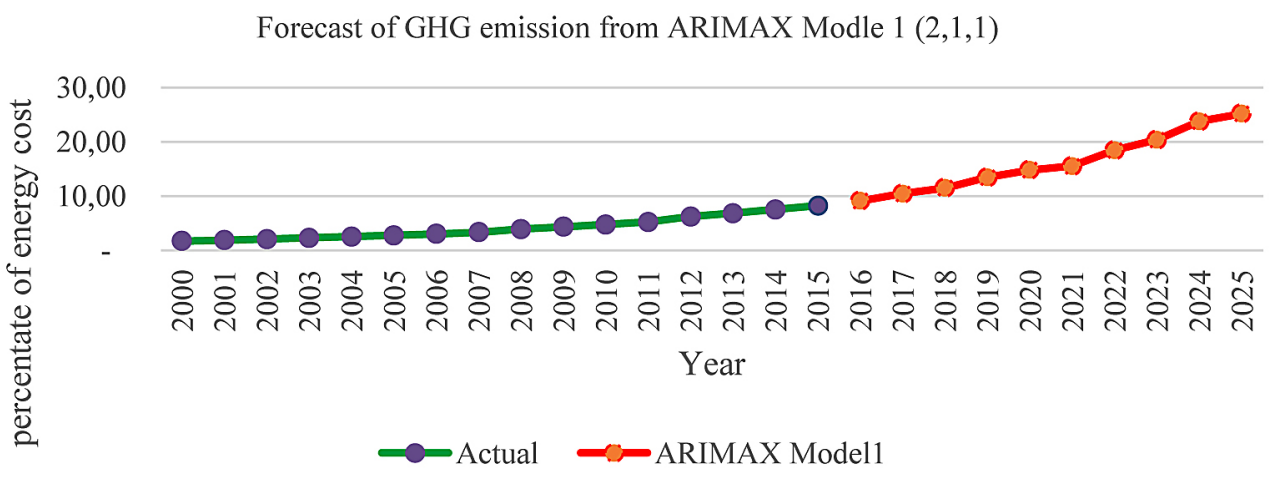

Figure 2. Forecasting from ARIMAX model $1(2,1,1)$

Forecast of GHG emission from ARIMAX Modle $2(2,1,2)$

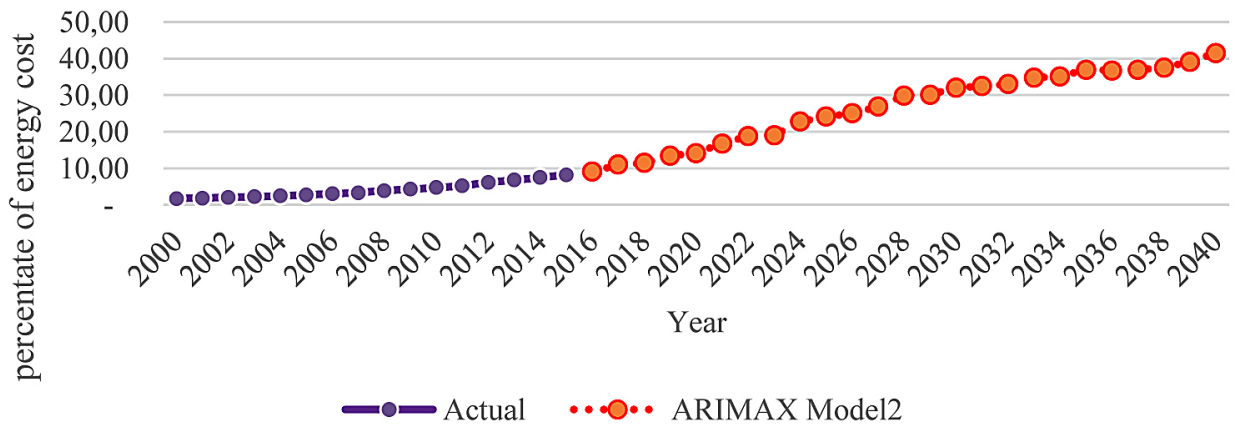

Figure 3. Forecasting from ARIMAX model $2(2,1,2)$ 
Table 6. The performance monitoring of forecasting model

\begin{tabular}{|c|c|c|c|}
\hline Forecast of GHG emission & RMSE & MAE & MAPE \\
\hline Model 1: ARIMAX Model $(2,1,1)(2016-2025)$ & 0.021 & 0.051 & 1.01 \\
\hline Model 2: ARIMAX Model $(2,1,2)(2016-2040)$ & 0.071 & 0.082 & 1.52 \\
\hline
\end{tabular}

on HP Filter to forecast the final energy consumption of Guangdong Province in China. However, there has not been any study done at all. Therefore, this study is a guide for the studying and applying in other countries in the future.

\section{CONCLUSIONS}

The result shows that iron and steel has the highest value of energy consumption and followed by cement, fluorite, air transport, road freight transport, hotels and places of loading, coal and lignite, petrochemical products, other manufacturing, road passenger transport, respectively. The result forecast shows that these models are effective in forecasting by measured by using RMSE, MAE, and MAPE.

The results forecast of each model is as follows: Model 1 and Model 2 shows that GHG emission will be increasing steadily and increasing at $25.17 \%$ (2025), 41.51\%(2040), respectively. The development of a sustainable development needs to be developed as three parts; economic, social, and environment.

The research shows that the environment is affected in a negative way that is the growth of economy and society, but reduced environmental continued. If left to its maximum carrying capacity, so have to policy and plan to increase the capacity of the environment's increase and impact to a minimum, with the measure of Green GDP, Clean Technology. The Law of society to treating about using the correct and most appropriate environment cut down on consumption society and should also be monitored for the consumption and production sectors caused some real benefit, less negative impact on the environment higher careful. Thus, this research would be useful for specify the sustainable development policy to achieve growth GDP, social, and environment.

\section{Acknowledgements}

This research is supported by Rachadapisek Sompote Fund for Postdoctoral Fellowship, Chulalongkorn University.

\section{REFERENCES}

1. Alizadeh M., Jolai F., Aminnayeri. M, Rada R. 2012. Comparison of different input selection algorithms in neuro-fuzzy modeling. Expert Syst Appl, 39, 1536-1544.

2. Asian Development Bank (ADB). 2014. Environment, Climate Change, and Disaster Risk Management. Manila. Asian Development Bank.

3. Assaad M., Boné R., Cardot H. 2008. A new boosting algorithm for improved time-series forecasting with recurrent neural networks. Inform Fusion, 9, 41-55.

4. Azadeh A., Asadzadeh S., Saberi M., Nadimi V., Tajvidi A., Sheikalishahi M. 2011. A neuro-fuzzystochastic frontier analysis approach for long-term natural gas consumption forecasting and behavior analysis: the cases of Bahrain, Saudi Arabia, Syria, and UAE. Appl Energy, 88, 3850-3859.

5. Azadeh A., Saberi M., Seraj O. 2010. An integrated fuzzy regression algorithm for energy consumption estimation with non-stationary data: a case study of Iran. Energy, 35, 2351-2366.

6. Barak S., Dahooie JH., Tichy' T. 2015. Wrapper ANFIS-ICA method to do stock market timing and feature selection on the basis of Japanese Candlestick. Expert Syst Appl, 42, 9221-9235.

7. Ciabattoni L., Grisostomi M., Ippoliti G., Longhi S. 2014. Fuzzy logic home energy consumption modeling for residential photovoltaic plant sizing in the new Italian scenario. Energy, 74, 359-367.

8. Ekonomou L. 2010. Greek long-term energy consumption prediction using artificial neural networks. Energy, 35, 512-517.

9. Hao J., Liu D., Li Z., Chen Z., Kong L. 2012. Power system load forecasting based on fuzzy clustering and gray target theory. Energy Proc, 16, 1852-1859.

10. Jovanovic' RZ., Sretenovic' AA., Z ivkovic' BD. 2015. Ensemble of various neural networks for prediction of heating energy consumption. Energy Build, 94, 189-199.

11. Lee Y-S., Tong L-I. 2011. Forecasting energy consumption using a grey model improved by incorporating genetic programming. Energy Convers Manage, 52, 147-152.

12. Lee Y-S., Tong L-I. 2012. Forecasting nonlinear time series of energy consumption using a hybrid dynamic model. Appl Energy, 94, 251-256. 
13. Leontief W.W. 1986. Input-Output Economics (2nd ed.). New York, Oxford University Press.

14. Mamlook R., Badran O., Abdulhadi E. 2009. A fuzzy inference model for short-term load forecasting. Energy Policy, 37, 1239-1248.

15. Office of the National Economic and Social Development Board. 2015. National Income of Thailand. Bangkok: NESDB.

16. Osorio G., Matias J., Catalão J. 2015. Short-term wind power forecasting using adaptive neuro-fuzzy inference system combined with evolutionary particle swarm optimization, wavelet transform and mutual information. Renew Energy, 75, 301-307.

17. Pappas SS., Ekonomou L., Karamousantas DC., Chatzarakis G., Katsikas S., Liatsis P. 2008. Electricity demand loads modeling using Auto Regressive Moving Average (ARMA) models. Energy, 33, 1353-1360.

18. Suganthi L., Iniyan S., Samuel AA. 2015. Applica- tions of fuzzy logic in renewable energy systems a review. Renew Sustain Energy Rev, 48, 585-607.

19. Suganthi L., Samuel AA. 2012. Energy models for demand forecasting - a review. Renew Sustain Energy Rev, 16, 1223-1240.

20. Thailand Development Research Institute (TDRI). 2007. Prioritizing Environmental Problems with Environmental Costs. Final report prepared the Thailand Health Fund. Bangkok.

21. Xie N-m., Yuan C-q., Yang Y-j. 2015. Forecasting China's energy demand and self sufficiency rate by grey forecasting model and Markov model. Int $\mathrm{J}$ Electr Power Energy Syst, 66, 1-8.

22. Yu S., Wei Y-M., Wang K. A. 2012. PSO-GA optimal model to estimate primary energy demand of China. Energy Policy, 42, 329-340.

23. Zhao H., Magoulès F. 2012. A review on the prediction of building energy consumption. Renewable Sustainable Energy Rev, 16, 3586-3592. 